\title{
(Semi-)automatic vector extraction of administrative borders from historical raster maps
}

\begin{abstract}
Keywords: image enhancing; Historical boundary data, Raster-to-Vector Conversion
Summary: Historical raster maps can be a useful source of information and allow us to travel backwards in time. The HistoGIS Project wants among other things also the creation of geodata from historical political/ administrative units to allow queries with this data. Therefore, already existing vector data is used but also scanned historical raster maps from the 19th and early 20th century. When it comes to the creation of new vector data the use of historical maps is inevitable. As the creation and extraction of vector data from raster maps can be very challenging especially when it is done manually by heads-up digitizing. Since this can be a very time-consuming and tedious task, the aim was to find an easy semi-automatic solution for extracting and vectorizing administrative borders from historical maps using open source tools. Therefore, different software tools and processes were tested. The main data source of this work builds the "Historischer Atlas der österreichischen Alpenländer".
\end{abstract}

\section{Introduction}

Historical border changes can help to answer a variety on open research questions. Spatial references become more and more important, not least of the "Spatial Turn" which places space or geographical space as a cultural entity ${ }^{2}$. Therefore the HistoGIS project from the Austrian Center for Digital Humanities and Cultural Heritage which is part of the Austrian Academy of Sciences wants to contribute this development. HistoGIS should support research projects with its historical geodata as an analytical tool, enrichment service, publishing platform as well as a workbench and stable repository (oeaw.ac.at). The project involves not only scanning, georeferencing and the extraction of administrative boundaries, but also collecting already existing shapefiles and adapting them to the projects data schema. Still the focus of the project is to generate data sets from the Habsburg Monarchy as granular as possible between the timespan of approximately 1780 until 1918 .

When it comes to the investigation of the already existing shape files, we realized how inaccurate some of the geometrical data was. And on the other hand, there are still a lot of political/ administrative entities missing.

At this point, where we need to compare the existing data with other maps on the one hand and where we need to generate new data from old historical maps on the other hand. To create new data from old maps is more complex and time intense. So the aim of this paper was to find and afterwards provide an easy solution for vectorizing historical administrative borders from old maps.

The methodology of the workflow that was used for creating and extracting vector boundaries from old maps, here preferably from maps of the "Historischer Atlas der österreichischen Alpenländer" is described below.

\footnotetext{
${ }^{1}$ Austrian Academy of Sciences, Vienna [anna.piechl@ oeaw.ac.at]

${ }^{2}$ Döring, J.; Thielmann, T. (Hrsg.) (2008): Spatial Turn. Das Raumparadigma in den Kultur- und Sozialwissenschaften. Transcript Verlag, Bielefeld.
} 


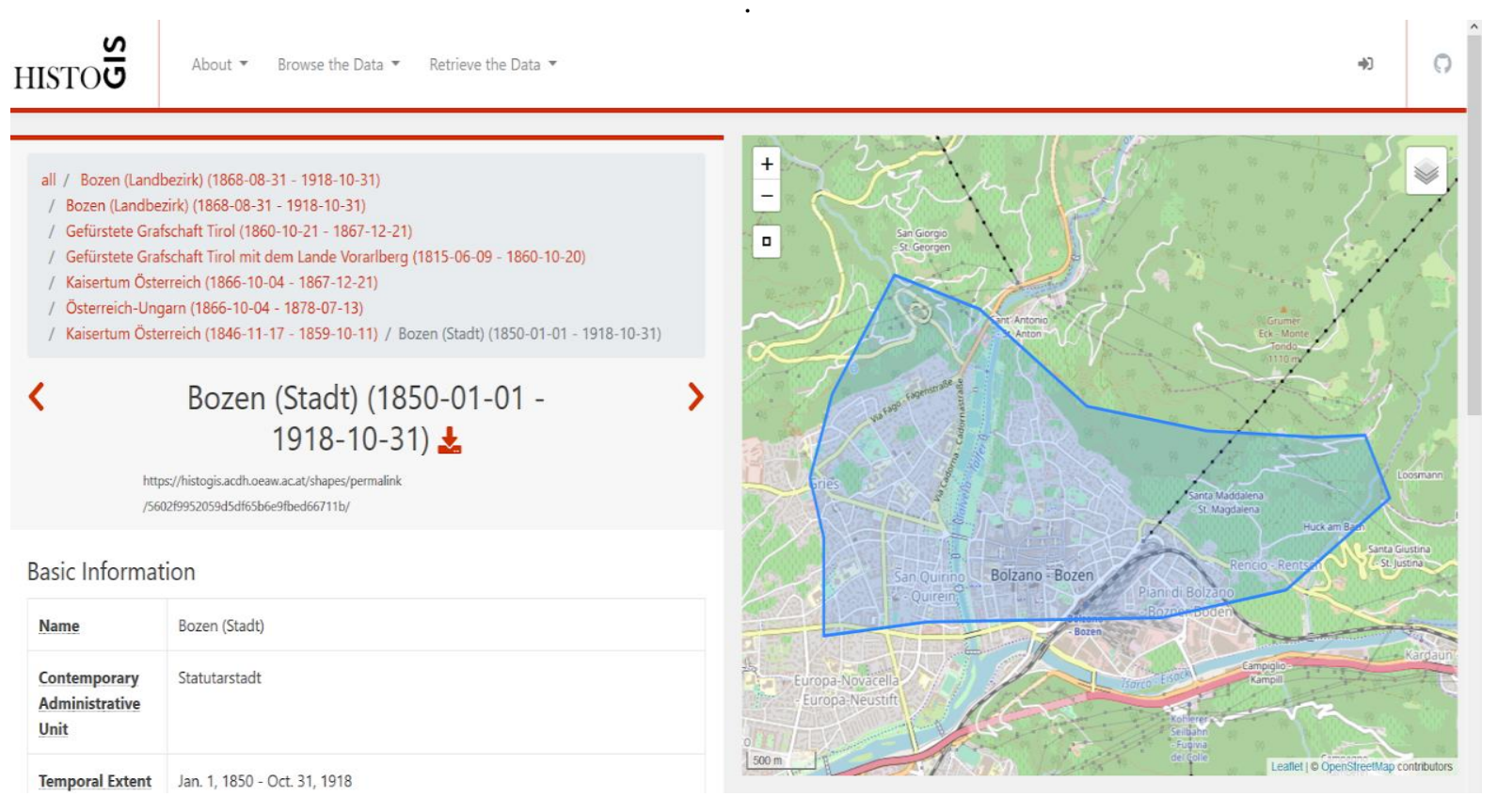

Figure 1. Example of a polygon with poor spatial accuracy (Screenshot HistoGIS App)

\section{Preprocessing}

After choosing an already scanned map for the region of interest it continues further to the next step. To be successful on (semi-) automated vectorization not only the step where it gets to the raster-to-vector conversion is important, but also to do some preprocessing, such as working on the image quality as well as enhancing and editing pixels. This is not only applicable for open source solutions but also for commercial ones ${ }^{3}$. Before on heads further to the GIS (Geographical Information System) part some image enhancement for the scanned map will take place. Here GIMP a pixel based open source image processing software was used. First it is important to emphasize the objects of interest of the map. Image mode at the beginning must be RGB (red, green, blue) which allows using Brightness and Contrast tool. In case of the map from the "Österreichischer Atlas der historischen Alpenländer". Brightness and Contrast were both increased for the value of 70 .

After colour brightness and contrast are adjusted, I play with the threshold of the canals of the map and increase the green value to get clearer borders. Whereby the threshold changes the raster into a black and white image. Black pixels represent pixels with a value out of the threshold range, white ones show pixels in the threshold range ${ }^{4}$.

As soon as the Image Enhancement is done the Fuzzy Select Tool was used to select the borders. After selecting, the selection gets copied in a new image and will be exported in TIFFFormat.

\footnotetext{
${ }^{3}$ https://www.iassistquarterly.com/index.php/iassist/article/view/914

${ }^{4} \mathrm{http}: / /$ search-ebscohost-com.uaccess.univie.ac.at/login.aspx?direct=true \&db=nlebk\&AN=923882\&site=ehostlive
} 


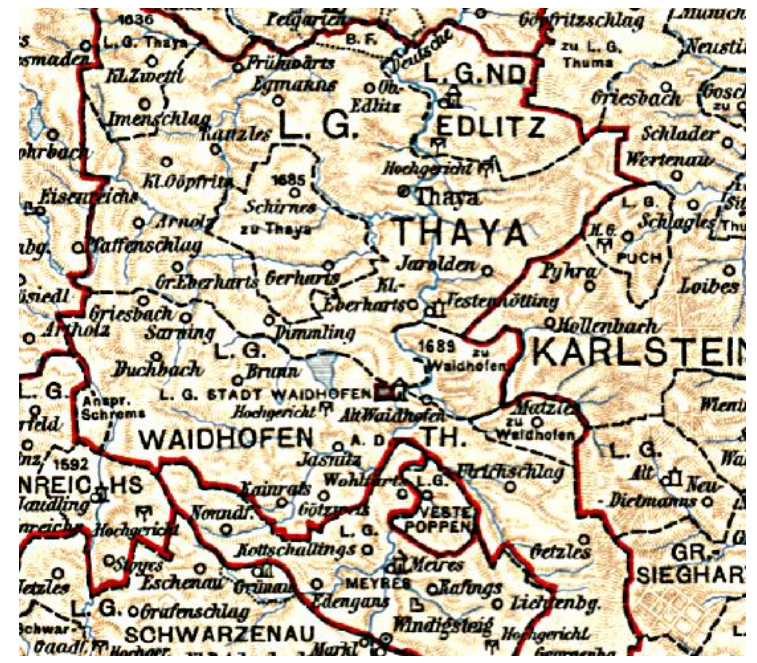

Figure 2. Image before pre-processing

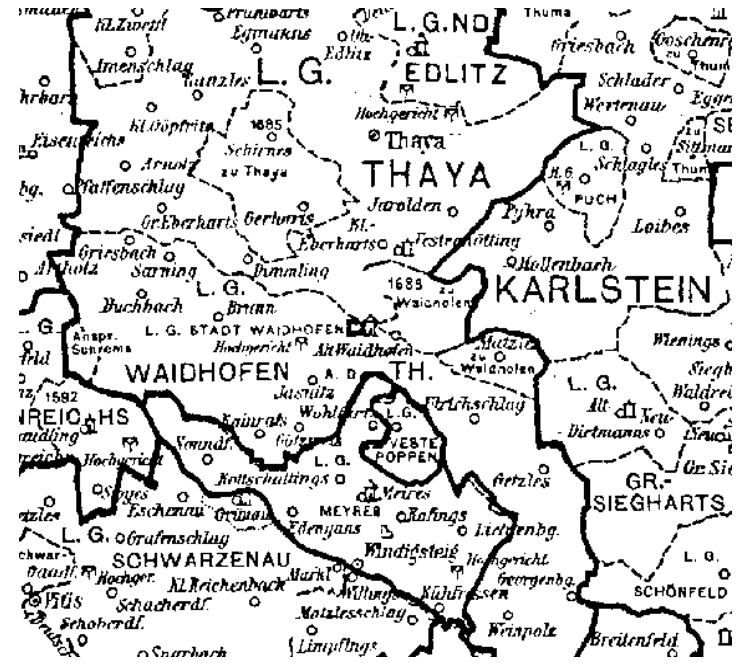

Figure 3. Image after pre-processing

\section{Georeferencing the selected borders}

To assign the raster map to geographic coordinates and a coordinate system it is necessary to georeference the raster image with the emphasized borders. For this step the Georeferencer Plugin in QGIS open source software was used. As a base map and therefore geospatial reference OpenStreetMap was used. Because a coordinate grid is not available in this map it is necessary to pick Ground Control Points (GCPs) manually. Beside the Ground Control Points, another very important factors are the Transformation Settings. There are three very common algorithms in use. A first-order polynomial transformation will scale, translate and rotate, a second-order polynomial transformation is able to handle some curvature, hence a third-order polynomial transformation allows even higher rates of distortion. We can find also projective option that offers rotation and translation of coordinates and a linear one on the other hand, which is used to create world files, but does not really transform the raster. Another option it to use the Thin Plate Spline algorithm which was determined for our map. As a resampling method Cubic Spline was defined. The reason for using these options was because they are useful for historical data because it is able to introduce local deformations in data and it is suggested for raster images with low quality ${ }^{5}$.

\section{Raster to Vector Conversion}

A semi-automatic vectorisation approach can help to reduce working time for a project. Especially when it comes to the vectorization of a larger number of maps it is worth to think about a somehow automatized option. A semi-automatic way working with non-commercial tools makes sense when someone deals with maps that have the same or similar colours or style and come from one source it is a good opportunity to use a prepared automatized workflow.

Once the preselected borders are georeferenced we want to head to the vectorization part. Therefore, the first step is to use the GDAL Tool Contour from the Raster extraction toolbox. It is supposed to be used for creating Digital Elevation Models (DEM). So, this is kind of a remote sensing techniques come into play. Here the default settings were used, except the

https://gracilis.carleton.ca/CUOSGwiki/index.php/Georeferencing_Raster_Imagery_in_QGIS_using_Vector_Dat a\# Adding_Control_Points 
Interval number between the contour lines got changed. For the maps of the "Historischer Atlas der österreichischen Alpenländer" the value had to be increased to at least 150 (Figure 4) to get a usable result. Testing shew that values below 150 would produce to many line objects which would make further working with the data even more difficult.

As a result, we get a line vector layer which shows the borders of the raster selection. With the settings done we received to lines. See in Figure 5. To receive a single border line, it is needed to find the centreline of the two outline border lines. After testing and not getting any good result a buffer came into play. Therefore, the next step was to create a buffer around the vectorized borders. To reach a "closing" result the Buffer Distance had to be set up to at least 180 meters (Figure 6). The tests showed that any lower value would not be enough to reach the wished results.

As a buffer result (Figure 7) we receive a polygon vector layer. The resulting buffer objects must be merged then and saved as a Polygon shapefile to extract the center lines afterwards.

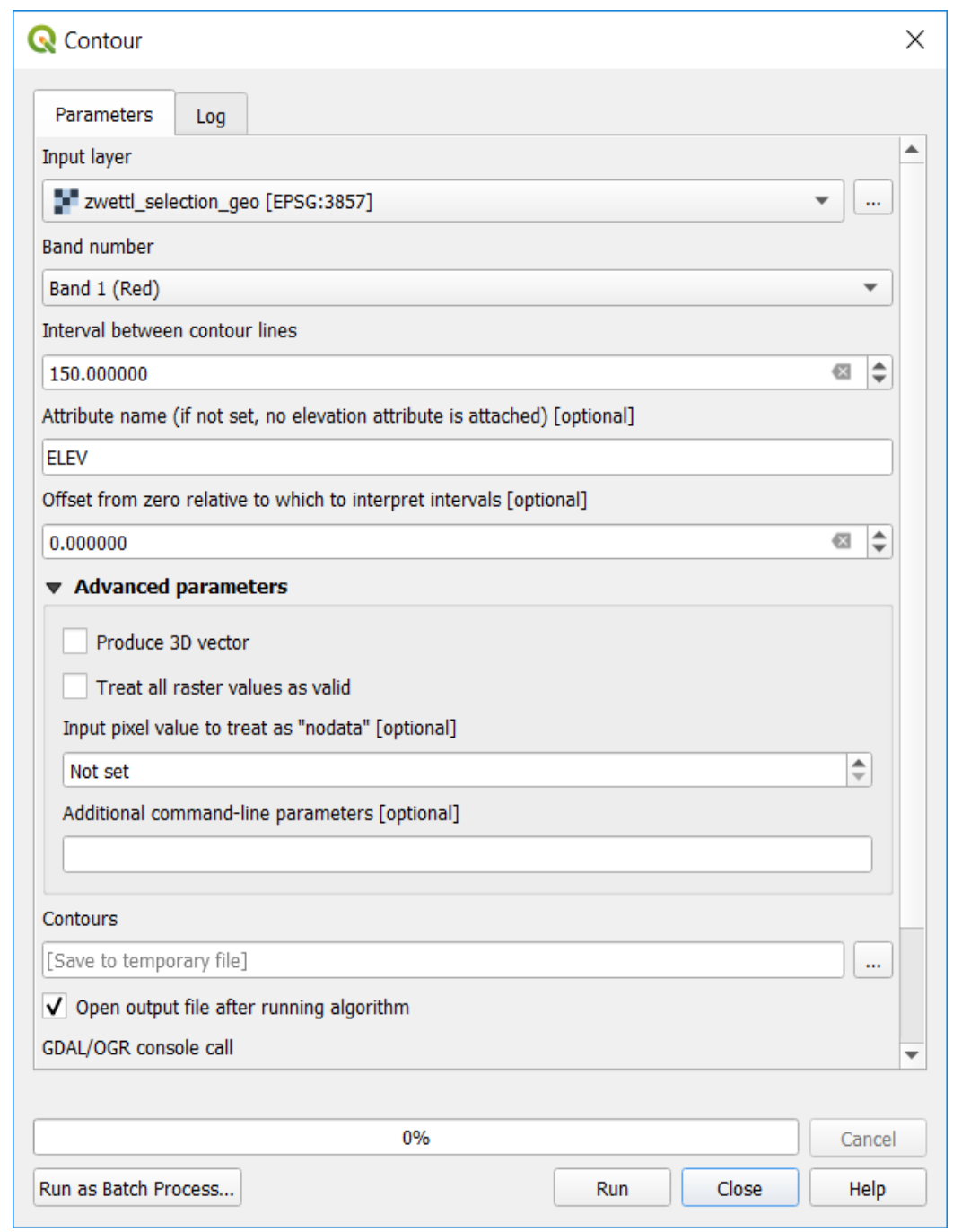

Figure 4. Screenshot Contour Tool Preferences 
International Workshop on Automatic Vectorisation of Historical Maps - 13 March 2020 - ELTE, Budapest https://doi.org/10.21862/avhm2020.05

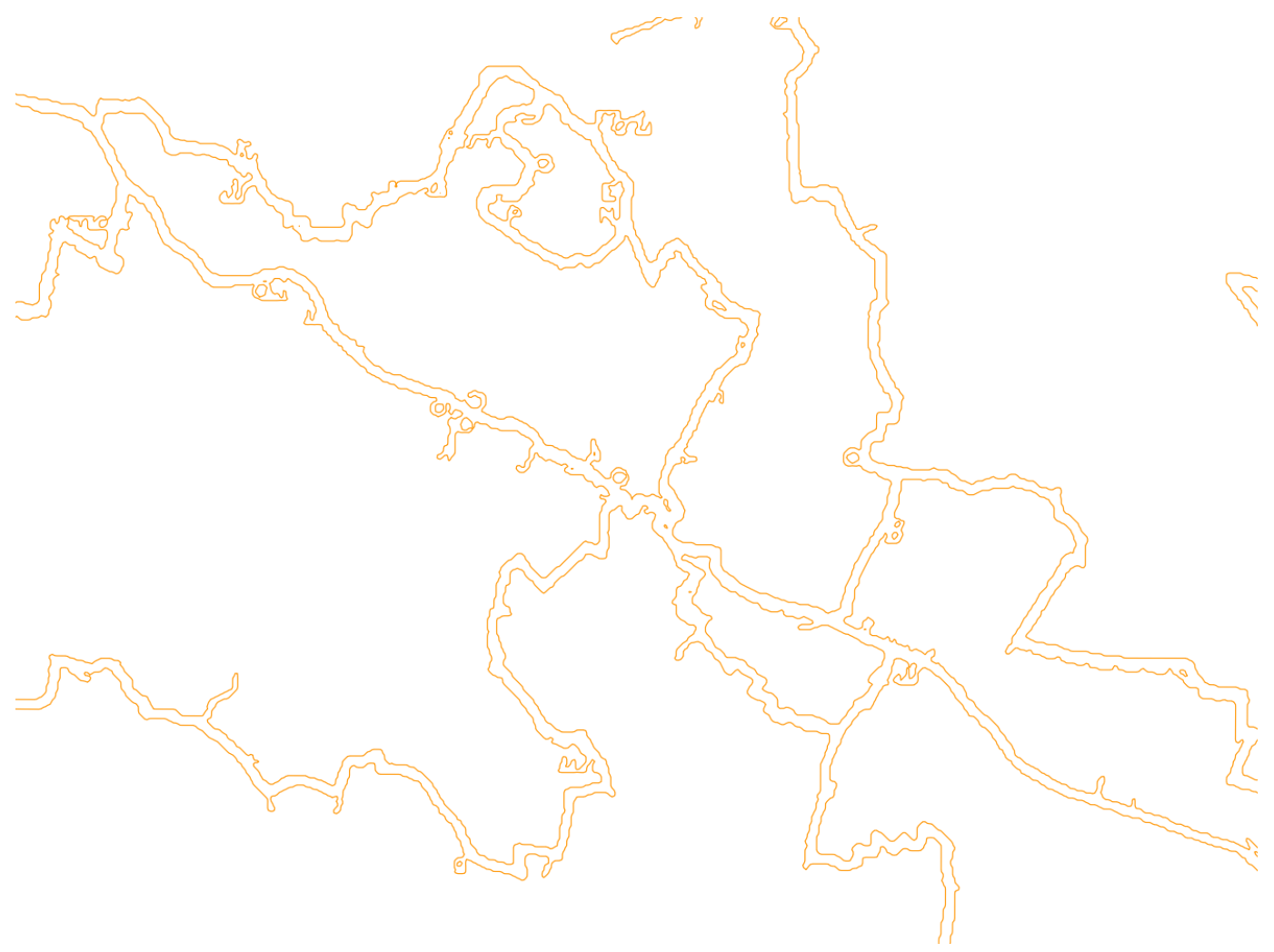

Figure 5. Results after running the Contour tool

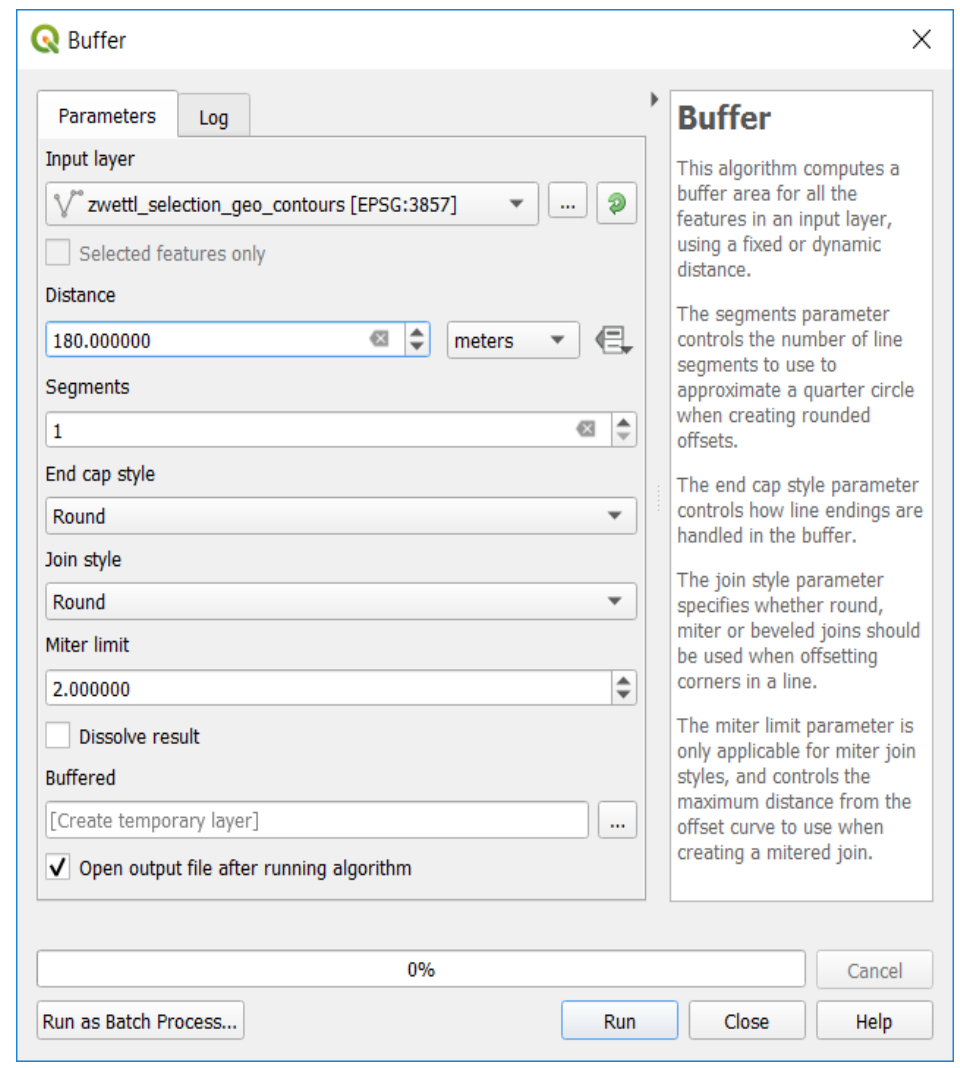

Figure 6. Buffer preferences 


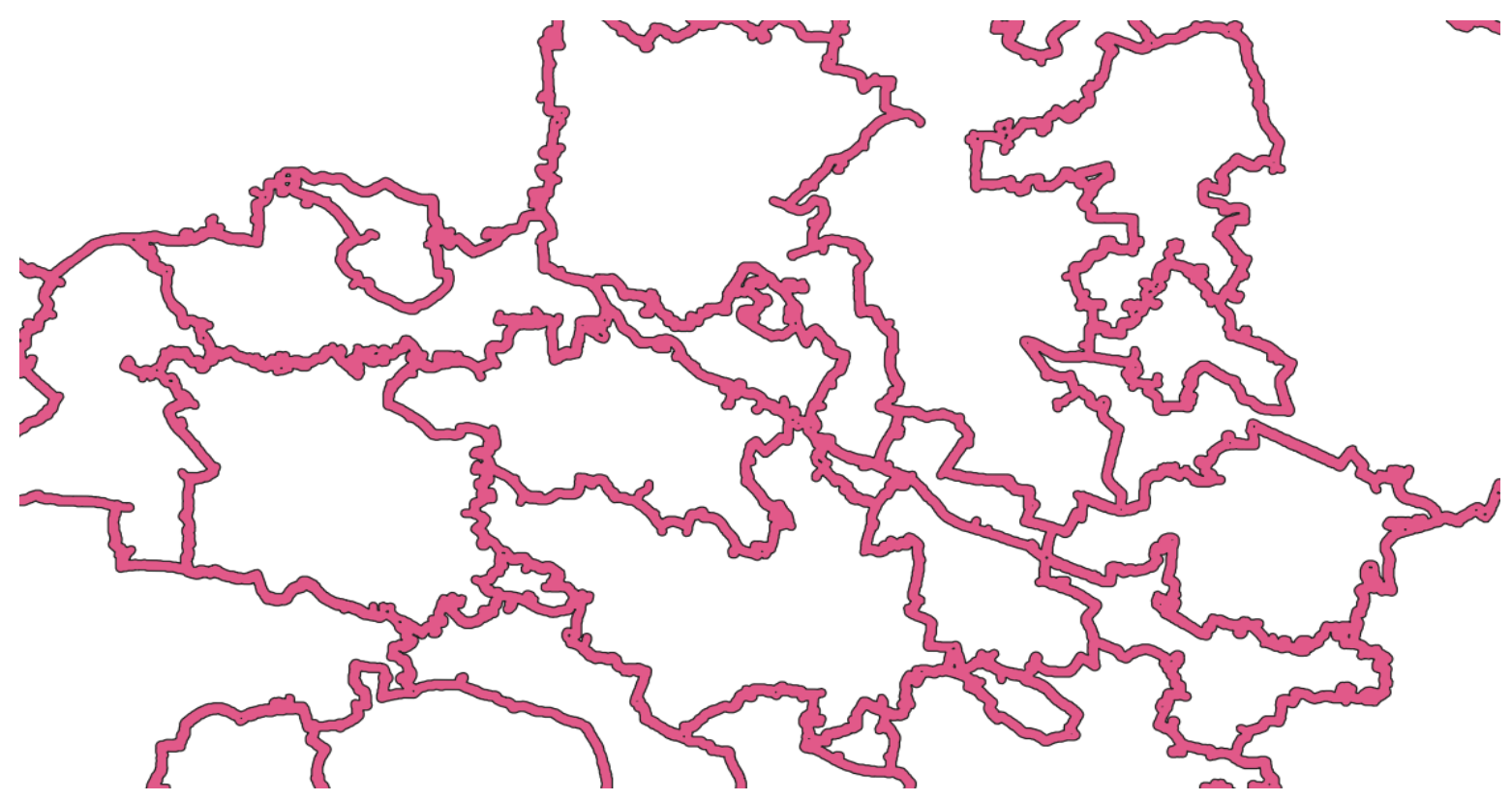

Figure 7. Results Buffer

\section{Using Open Jump for Skeletonizing}

After testing several tools and methods in QGIS that did not show satisfying resuls for a skeletonize or center line extraction process the solution was to try a different QGIS tool. The open source software OpenJUMP provides a Skeletonizer Plugin to be tested. The GIS-Software and tools are freely downloadable. This tool creates skeletons of polygon objects. To get the centerline of our buffer polygon the buffer shape file, that was created beforehand in QGIS must be loaded in the OpenJUMP Software. See preferences in Figure 8). As a result, we get a connected line shapefile (Figure 9). After the process we export the data as a shape file.

\begin{tabular}{|c|c|c|c|}
\hline \multicolumn{3}{|l|}{ Skeleton } & X \\
\hline \multirow{7}{*}{$\begin{array}{l}\text { Polygon Skeletonizer } \\
\text { - Parameters by feature will } \\
\text { automatically compute suitable } \\
\text { parameters for each feature } \\
\text { - Minimum with determines how } \\
\text { precise the result will be (it will } \\
\text { also impact performance) } \\
\text { - Minimum fork length } \\
\text { determines how many } \\
\text { secondary forks will be kept } \\
\text { - Beautify ends will avoid small } \\
\text { artifacts (ex. when skeletonizing } \\
\text { rectangles) }\end{array}$} & Source layer & \multicolumn{2}{|c|}{$\square$ zwett|_selection_geo_contours_buffered $\vee$} \\
\hline & \multicolumn{3}{|c|}{$\checkmark$ Automatic width computation } \\
\hline & \multirow{2}{*}{$\begin{array}{l}\text { Minimum width } \\
\text { Minimum length of forks }\end{array}$} & 182.9510415291776 & \\
\hline & & 10.0 & \\
\hline & \multicolumn{3}{|c|}{$\square$...relative to mean width } \\
\hline & \multicolumn{3}{|c|}{$\square$ Snap edge ends to polygon boundary } \\
\hline & \multicolumn{2}{|c|}{$\square$ Display a layer with initial voronoi edges } & Snap edg \\
\hline & $\underline{\mathrm{O} K}$ & & \\
\hline
\end{tabular}

Figure 8. Skeletonizing buffered border selection - preferences 
International Workshop on Automatic Vectorisation of Historical Maps - 13 March 2020 - ELTE, Budapest https://doi.org/10.21862/avhm2020.05

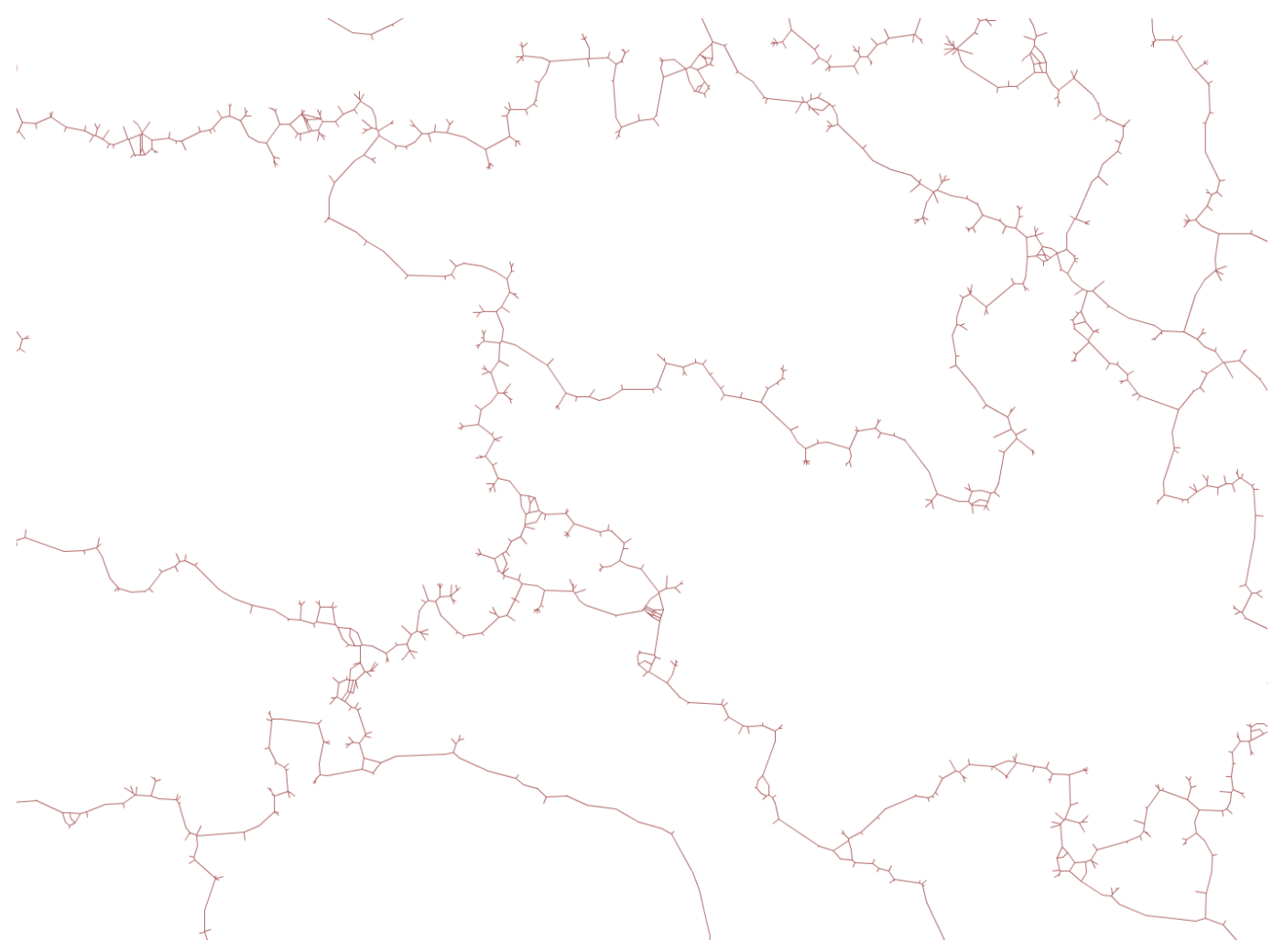

Figure 9. Result Skeletonizing

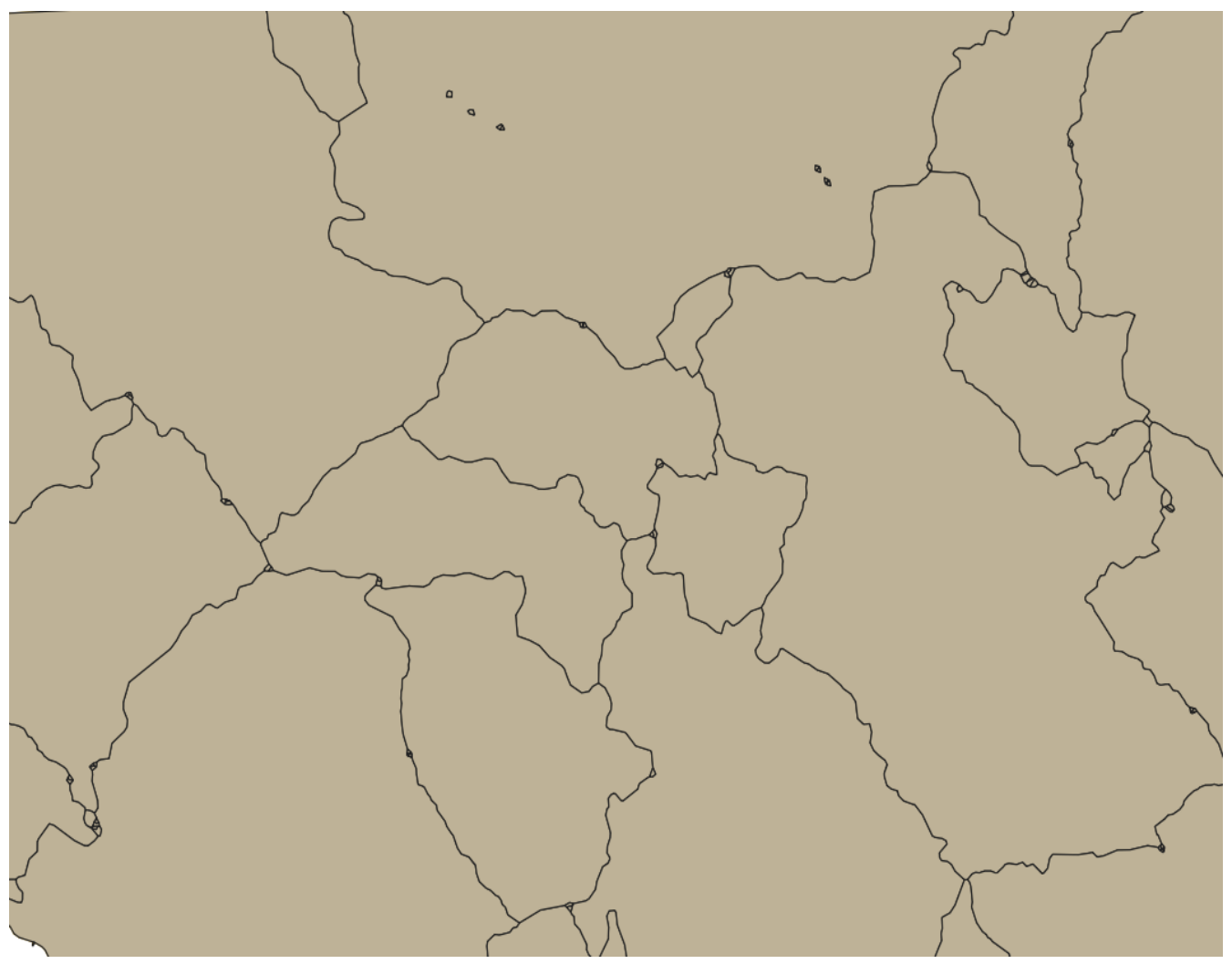

Figure 10. Polygonized Boundaries 


\section{Creating final Boundary Data set}

To get the final boundary data set we load the skeletonized results back into QGIS. As we wish to have polygons for our political entites we transform our lines into polygons. To reach this we must use Polygonize tool. As shown in Figure 11, some of the boundaries do not close, therefore the end of the lines will be closed, by doing this the Polygonize tool will transform the line features into polygons, see in Figure 12. The result is okay but not perfect. Within the polygons there are still small areas that must probably be removed manually or with a cleaning tool. This leads back to the poor image segmentation.

\section{Conclusion}

The research in this paper presents one easy solution for extracting vector data from historical maps. Although this paper shows only one way in an easy manner for doing this process but still it lets us know that there are several options when using non-commercial software such as GIMP, QGIS or OpenJUMP. The tools show usable results, even if they are still in need of improvement. The testing shows that it is not possible to be successful without doing any preprocessing. And still it is no easy to find an open source solution that is easy to deal with for people who have low programming knowledge.

\section{References}

Döring, J.; Thielmann, T. (ed.) (2008): Spatial Turn. Das Raumparadigma in den Kultur- und Sozialwissenschaften. Bielefeld: Transcript Publishing.

https://doi.org/10.14361/9783839406830

Graser, A. (2014) Learning QGIS - Second Edition. Birmingham: Packt Publishing

(Community Experience Distilled). Available at: http://search-ebscohost-

com.uaccess.univie.ac.at/login.aspx .direct $=$ true $\& d b=$ nlebk $\& A N=923882 \&$ site=ehost-live (Accessed: 13 February 2020).

Peller, Peter. (2018). From Paper Map to Geospatial Vector Layer. IASSIST Quarterly. 42. 1-24. 10.29173/iq914. https://doi.org/10.29173/iq914 